\title{
Employment law
}

\section{In this article the British Dental Association's Practice Management Consultant Neeta Udhian sets out answers to some common questions asked of the BDA's Practice Support Team.}

Employment law covers a wide range of issues in the workplace and is often complex. Both employer and employee have responsibilities to each other.

\section{When should an employee expect to be issued with a contract of employment?}

The Employment Rights Act 1996 requires that employers provide employees with a written statement of particulars of employment no later than two months after starting employment.

A contract is an opportunity for the employer to define the employment relationship with the employee. The contract of employment should set out clearly the employer's expectations, rules and benefits.

\section{Does anything have to be put in writing} when a verbal warning is issued? In order for a verbal warning to be valid, a disciplinary procedure must be followed. That is, the employee must be invited to a disciplinary meeting in writing stating the date, time and location of the meeting as well as the reason for the disciplinary. The disciplinary invitation should also state that the employee may be issued with a verbal warning and that they can attend accompanied by a work colleague or trade union representative.

The employer must then hold a disciplinary meeting and take detailed notes allowing the employee to respond to the allegations against them. The final stage of the process is to write to the employee and confirm that they have been issued with a verbal warning.

\section{Do dental nurses need to} maintain their GDC registration while on maternity leave?

There is no requirement by the General Dental Council (GDC) for dental nurses to maintain their GDC registration while on maternity leave. However, if a dental nurse on maternity leave fails to renew her registration she will have to apply for restoration when she returns to work. The GDC restoration fee is currently $\mathfrak{E} 120$. In addition to this, the dental nurse will also have to supply a doctor's report, which they may be charged for.

All dental nurses must renew their registration with the GDC by 31 July of each year. The current renewal fee is $£ 96$. If a dental nurse applies for restoration a few months before July, s/he will still have to pay the renewal fee in July.

What are the conditions for requests for flexible working to be considered?

In order to be eligible to make a request for flexible working a member of staff:

- Must be an employee

- Must have worked for the employer for 26 weeks continuously before applying

- Must not have made another application to work flexibly under the right during the past 12 months

- Must have or expect to have parental responsibility of a child aged 16 or under or a disabled child under 18 who receives Disability Living Allowance (DLA)

- Is the parent/guardian/special guardian/ foster parent/private foster carer or is the holder of a residence order or the spouse, partner or civil partner of one of these and is applying to care for the child

- Is a carer who cares, or expects to be caring, for an adult who is a spouse, partner, civil partner or relative; or who although not related to the employee, lives at the same address as him or her.

We would always advise employers to listen to employees' requests and consider them before replying.

\section{A team member has complained of being bullied by another. \\ As practice manager I am sure that the allegations are not true. How seriously should I take them? A simple rule: never, ever, ignore a grievance. \\ Never make assumptions about a complaint or grievance.}

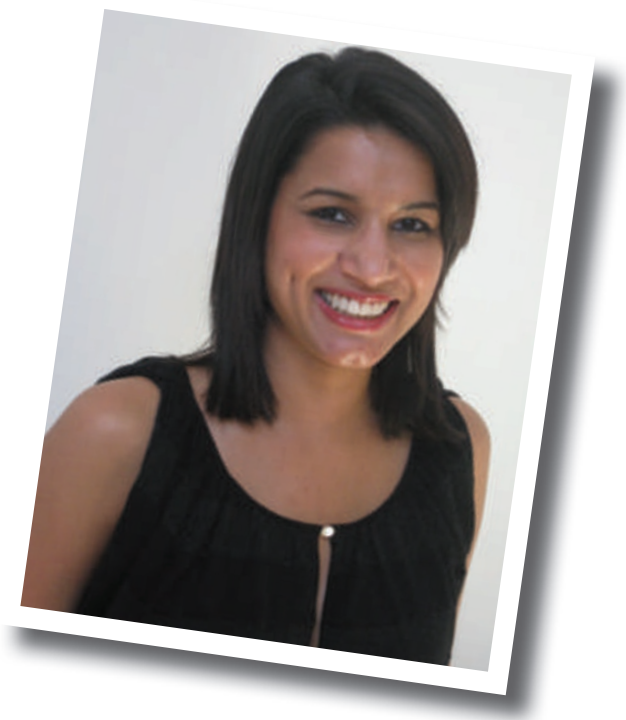

Invite the staff member who made the complaint to a grievance meeting. Inform them that they have the right to be accompanied by a work colleague or union representative. Listen to what they say. Try to understand their point of view. You can then investigate their complaint or grievance by speaking to the other team member and anyone else who may be a witness or have relevant information. Once you have got all the information you need, you will be in a position to reply to that grievance properly.

Make sure you follow your practice grievance procedure.

A member of staff has not attended work for the last five Mondays in a row, each time for a different reason. As practice manager is there anything I can do?

The practice should invite the employee in for a meeting to discuss the staff member's high level of sickness absence and the fact that they have noticed a pattern. This meeting should be used to explore whether there are any underlying medical problems the employee has not informed the practice about. If there do not appear to be any underlying medical problems, the practice should set the employee attendance targets and inform him/her that if $\mathrm{s} /$ he fails to meet these, disciplinary action will be taken against him/her.

The BDA model contract states that if an employee is absent for four or more occasions in any one calendar year, the employee will be required to bring in a doctor's note for any subsequent absences regardless of their length.

There is a BDA Training essentials course called Employment law - rights and responsibilities. The cost for non-dentist members of the team is £95. For details of dates and locations visit www. bda.org/training. 